\title{
Climate Variability and Determinants of its Adaptation Strategies; the Case of Coffee (Coffea

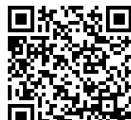 arabica) Producer Farmers at Abeshege Woreda, Ethiopia
}

\author{
Tsegamariam Dula* \\ Department of Agricultural Economics, Wolkite University, College of Agriculture and Natural Resource, Ethiopia
}

Submission: August 08, 2018, Published: September 05, 2018

"Corresponding author: Tsegamariam Dula, Department of Agricultural Economics, Wolkite University, College of Agriculture and NaturalResource, PO Box. 07, Wolkite, Ethiopia; Tel: 910063096; Email: tsegamariamd@gmail.com

\begin{abstract}
The share of agriculture in the Gross Domestic Products (GDP) of Ethiopia is very significant. Although agriculture is undeniably a key economic sector in Ethiopia, it is the most vulnerable to the impacts of climate variability. An attempt to reduce the impacts of climate-related problems requires appropriate policy responses. A number of studies on climate variability adaptation recognize the importance of agroecologically based studies for designing context-specific policies and programs to climate variability adaptation. Therefore, this study was carried out with objectives of examining the variations of climate variability and its determinants of farmers' decision to undertake adaptation measures to climate variability using a case study in Abeshege woreda. The primary data was collected from 145 sample households using a survey questionnaire and was analyzed using both descriptive statistics and econometric methods. The logit model was used to identify the determinants of climate variability adaptation decision. The result of the logit regression model shows that perception, education level, farm size, access to credit service and total family size are among the factors which are positively and significantly affecting the farmers' adaptation decision. Besides, the results of linear regression show that the amount of rainfall received and temperature significantly affect coffee production in the study area. Therefore, first should recognize the farmers' preferences for climate variability adaptation strategies to design and implement interventions that address capacity, technology and information needs of households experiencing different climatic problems..
\end{abstract}

Keywords: Climate variability; Adaptation strategies; Determinants

Abbreviations: GDP: Gross Domestic Products; Pas: Peasant Associations; NMA: National Metrological Agency; IPCC: Intergovernmental Panel on Climate Change: FDRE: Federal Democratic Republic of Ethiopia

\section{Introduction}

Climate change already had (and will continue to have) a severe and negative effect on coffee production throughout the world. In Ethiopia, rapidly increasing temperatures kill the plants at an alarming rate. Pests and disease that target coffee plants have risen in prevalence. Unless action is taken to slow down climate change or find alternative ways to keep coffee plants alive, Ethiopia will be in danger due to the importance of coffee production for their economies [1]. Rising temperatures and erratic rainfall are threatening sustainable coffee production by enabling outbreak of diseases and infestations of insect pests that decrease the quality and yield of coffee berries [2].

The same is true for smallholder farmers of Abeshege woreda, where this study has been conducted. In the past few decades, rainfall variability and other meteorological shocks greatly affect coffee production [3]. In Abeshege, woreda rainfall has been declining in recent years and this has affected crop and livestock production. Heavy rains and frost/coolness are possible hazards which have devastating effects on coffee production. The main indicators of approaching crisis include a delayed start of the rainy season or long periods without rain at a critical stage of the rainy season [4]. Therefore, the ultimate goal of this study was specifically to assess the perception of household on climate variability and change, to determine factors that influence farmers' choice of adaptation strategies to climate variability, to identify adaptation strategies used by farmers' in response to climate variability to generate empirical evidence about climate variability and their effect on coffee production of the smallholder farmers of Abeshege woreda. Moreover, the results can create awareness among smallholder farmers about the effect of climate variability and how to maintain sustainable adaptation strategies.

\section{Materials and Methods}

\section{Description of the study area}

Abeshege woreda is one of the rural woredas of SNNP located about $155 \mathrm{~km}$ south of Adiss Abeba along the Adiss Abeba to Jimma asphalt highway and $233 \mathrm{~km}$ south west of Hawassa 
city [4]. The woreda is bounded in the north, south and west by Oromia regional state and in the east by Cheha woreda and Kebena woreda. The absolute location of the study area extends $8027^{\prime} 30^{\prime \prime} \mathrm{N}$ to $38010^{\prime}$ 50" E. The climate of Abehsege woreda ranges from cool to warm. The annual average temperature of the area is $21.25^{\circ} \mathrm{C}$. The annual average Rainfall is range from $801 \mathrm{~mm}$ up to $1400 \mathrm{~mm}$ within the last 10 years. The area receives a bimodal rainfall where the small rains are between March and April while the main rains occur mainly from July to September. During the main rains, all crops grown in the area are planted including coffee, maize, teff, wheat, pepper, haricot bean, sorghum and millet. Agro ecologically, The Woreda consists of 75\% "kola" and 25\% "Woina Degas" having two major seasons, namely Belg and Meher and irrigation is practiced in some areas i.e. Derelafto and Kulito. Wheat, nug and chickpea are major crops cultivated in meher season. On the other hand maize, Teff and sorghum are cultivated in Beleg season. The altitude of the woreda ranges from 1001 to 2000 meter above sea level, but most of the woreda is found at about 1800 meter above sea level. Except for few hills, the woreda has agriculturally suitable land in terms of topography.

\section{Methods of data collection}

To fulfill the objectives of the study, both quantitative and qualitative data were gathered from primary and secondary sources. Quantitative data were generated through household survey by employing structured interviews from a total of 145 respondents of two PAs namely Tachgnnaw geraba and Tatesa. These kebeles were selected based on their potential on coffee production. In addition, relevant secondary data like monthly and annual rainfall, mean, maximum and minimum temperature, population of the study kebeles and coffee yield $(\mathrm{kg} / \mathrm{ha}$ ) for a period of 1997-2016 were collected from reports, records and other published documents from the concerned offices. The qualitative data were gathered through focus group discussion, key informant's interviews, informal discussions with farmers, and personal observations.

\section{Sampling procedures and sample size}

A two-stage sampling technique was employed to select peasant associations (PAs) and sample respondents. In the first stage, selection and categorizations of kebele's was done in consultation with woreda agricultural office and available documents which provide information about coffee production practice of the area. There are 23 coffee producer kebeles, of which 18 are high potential and 5 medium. Based on these, kebeles were subdivided into two strata; high potential and medium potential areas. As a result, two Peasant Associations (PAs), one from highly potential and one from medium potential randomly selected. Finally, 145 household heads were selected randomly from the selected Peasant Associations (PAs) using the following formula [5].

\section{Method of data analysis}

Descriptive statistics: Descriptive statistical tools were used for the study such as, mean, percentage and frequency of occurrence for the effects of Climate variability on coffee production. Determination of variations in temperature Seasonal and annual trends of maximum and minimum temperatures were computed from monthly temperature data and trend and patterns determined by means of graphs and trend lines. The trend line equation $y=a X+b$ was used to describe the changes in temperature. Determination of variations in rainfall Seasonal and annual patterns were computed from monthly rainfall data, and the variations were illustrated by means of graphs and trend lines. The rainfall data was disaggregated into two growing seasons February to May (FMAM) and June to September (JJAS). The main growing season is JJAS while the second growing season is FMAM. The trend line equation $y=a X+b+e$ was used to describe the changes in rainfall.

Econometric analysis: Econometric model plays a great role in research works for identifying the relation between different factors. For this study; logistic regression model were used to analyze the determinants/factors of adaptation mechanisms.

Logistic model: For this study the logit model was selected to analyses factors affecting farmer's decision to adopt any Climate variability adaptation strategy. The dependent variable i.e., adaptation strategy to Climate variability is dichotomous in nature and can be represented by dummy variables. When dealing with a dichotomous dependent variable my main interest is to assess the probability that one or other characteristics is present [6]. In this study a dichotomous dependent variable adaptation strategy to Climate variability be taken as dependent variable and has been represented in the model by dummy variable taking the value of 0 if a household adopt and 1 otherwise.

The main assumption of logistic regression is that the natural logarithm of the odds ratio or probability of being in a response category is linearly related to the explanatory variables. Regression coefficients are estimated using the method of maximum likelihood. The log of the odds ratio, the logit, transforms a variable constrained between 0 and 1 into a continuous unbounded variable. The cumulative logistic probability function is specified econometrically as

$$
P_{i}=F\left(Z_{i}\right)=F\left[\alpha+\sum_{i=1}^{n} \beta_{i} X_{i}\right]=\left[\frac{1}{1+e^{-\left(\alpha+\sum \beta_{i} X_{i}\right)}}\right]------1
$$

Where, Pi represents that the probability that $\mathrm{i}^{\text {th }}$ farmer is being adopt adaptation strategy to Climate variability given $\mathrm{Xi}$ variable.

Xi: represents the $\mathrm{i}^{\text {th }}$ farmer explanatory variables, $\mathrm{i}=1,2$, 3....., $\mathrm{n}$

Zi: a linear function of $\mathrm{n}$ explanatory variables (Xi)

e: represents the base of natural logarithms (2.718)

$\beta_{i}$ : are regression parameters to be estimated, where is intercept and 
$\beta_{1}, \beta_{2}, \ldots . ., \beta_{n}$ : are slope coefficients of the explanatory variables in the model.

For this study household participation in adaptation strategy (Yi) depend on the various explanatory variables $\mathrm{X}_{1}, \quad \mathrm{X}_{2}, \mathrm{X}_{3}, \mathrm{X}_{4}, \mathrm{X}_{5} \ldots \ldots \ldots \ldots \ldots . . . . . . . . \mathrm{Xn}$ which can be modeled a

Where; Yi; is household participation in adaptation strategy to Climate variability

$\mathrm{Xi}$; explanatory variables which have associations with adaptation strategy

$\mathrm{Ui}$; is the error term

$\beta_{1}, \beta_{2} \ldots \beta_{n}$ : are slope coefficients of the explanatory variables in the model (Table 1).

Table 1: Summery for independent variable included in the final model estimation.

\begin{tabular}{|c|c|c|}
\hline Variable & Description & Expected Sign \\
\hline Age & Continuous & + \\
\hline Prcpn & Discrete & + \\
\hline Eduleve & Dummy variable & + \\
\hline Tfmsize & Continuous & + \\
\hline Acscrdt & Dummy variable & + \\
\hline Texns & Dummy variable & + \\
\hline Tfmsize & Continuous & + \\
\hline Sex & Dummy variable & $+/-$ \\
\hline
\end{tabular}

Results and Discussion

\section{Farmers perceptions to climate variability}

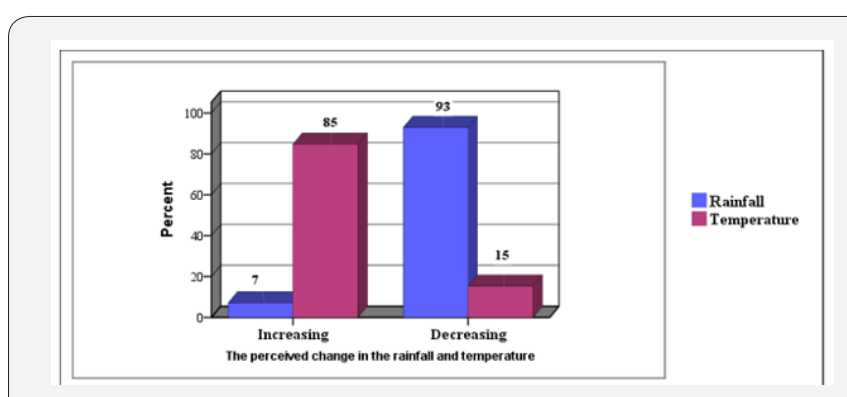

Figure 1: Farmers perceptions to Climate variability (rain fall and temperature).

Figure 1 indicates that the Perceptions of farmers with respect to changes in temperature and rainfall variability were in line with empirical analysis of temperature and rainfall trends of metrological data station. the direction of the perceived changes in rainfall and temperature level by the farmers in the study area indicate that about $7 \%$ and $85 \%$ of the respondents perceived an increment in the level of rainfall and temperature respectively while about $93 \%$ and $15 \%$ of the respondents had perceived a reduction in the level of the rainfall and temperature respectively. From the data we can conclude that majority of the farmers in the study area perceived a decrease in the level of the rainfall but an increase in the level of temperature. These findings are in line with other similar [7], Find that farmers are perceptive of climate variability, which they associate with rainfall, temperature, and other extreme weather events. These results are indicative of farmers' likelihood to adapt to climate variability if other factors that hinder them from adapting are addressed.

\section{Adaptation strategies to climate variability used by farmers in abeshege woreda}

The result show that (Figure 2) soil and water conservation is highly preferred climate variability adaptation strategy as it is indicated by $24.14 \%$. Whereas, small scale irrigation by $17.24 \%$ and changing planting date by $13.1 \%$ of respondents. In the study area improved crop and livestock variety and seek off-farm employment is also used as climate variability adaptation strategy by $12.76 \%$ and $12 \% .41$ of the respondents respectively. However, planting trees is the least implemented adaptation strategy by $10.34 \%$ of respondents. The study also revealed that farmers adopt strategies as a way of spreading risks on the farm and this is in line with the finding of [8]. Adaptation strategies can also serve as insurance against rainfall variability [9]. Farmers' respond to climate change stimuli by undertaking activities that help them cope with adverse consequences, reduce vulnerability and potential damages from climate change, and help them to adjust to climate change and variability [10].

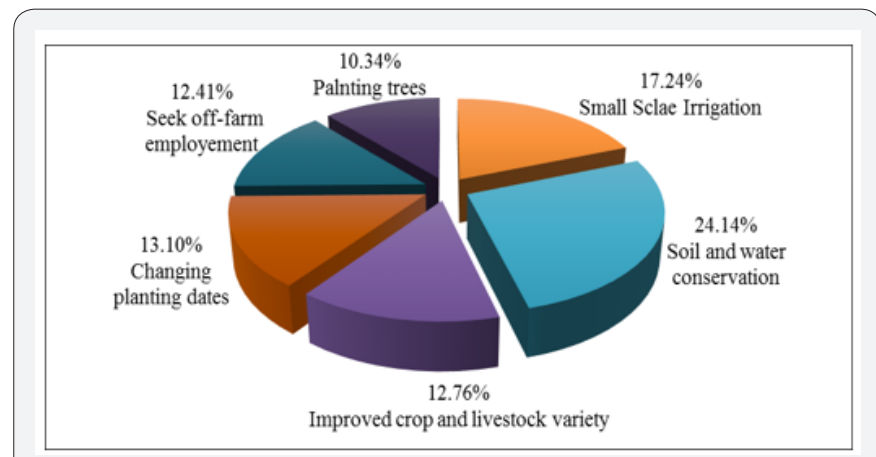

Figure 2 : Climate variability adaptation strategies used by the farmers in Abeshege Woreda.

\section{Seasonal rainfall and variability (belg and meher) trends}

Apart from annual rainfall, season-to-season variability of rainfall within a season is critical to agriculture [11]. In this study, the rainfall data was disaggregated into two growing seasons belg (February to May) and meher (June to September). The main growing season is meher while the second growing season is belg. Both exhibit variation in seasonal rainfall in amount and monthly spread. Analysis of belg and meher rain has shown decline trend from 1996 to 2015 . It has decreased by about $7 \mathrm{~mm}$ and $31 \mathrm{~mm}$ every year respectively during the past two decades (Figure 3). In addition, year to year variability of rainfall (CV\%) of meher and belg season was $37 \%$ and $35 \%$ respectively, which indicates there was higher year to year variability of rainfall in meher than belg season. 


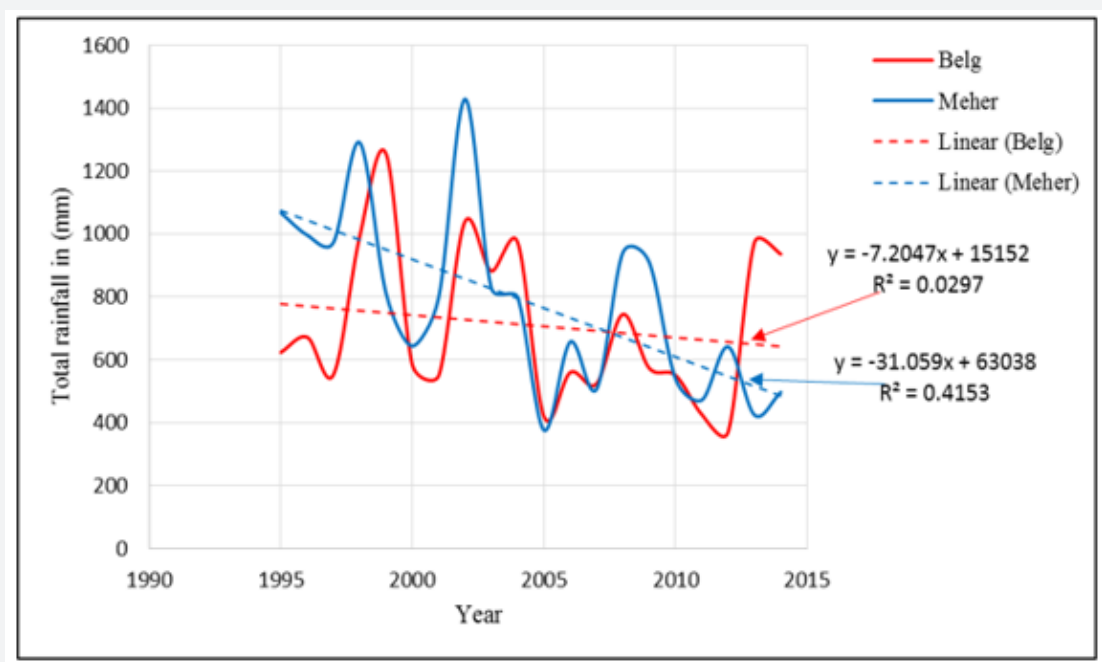

Figure 3 : Seasonal Rainfall and variability (Belg and Meher) Trends.

\section{Annual temperature variability and trends}

The analysis of temperature data obtained from National metrological agency (NMA) tends to support the perception of the majority of respondents regarding temperature trends. The data indicates that the maximum and minimum temperature is increasing annually by $0.035{ }^{\circ} \mathrm{C}$ and $0.30{ }^{\circ} \mathrm{C}$ respectively (Figure
4). The above result are compatible with a national study which found broadly consistent warming trend or rising minimum and maximum temperatures over the past fifty years. Although the observed weather data reveals the direction of change in temperature that did not only rise but also varied across the years. In addition to increasing trend in temperature, there is also annual variation in the form of cumulative monthly average temperature.

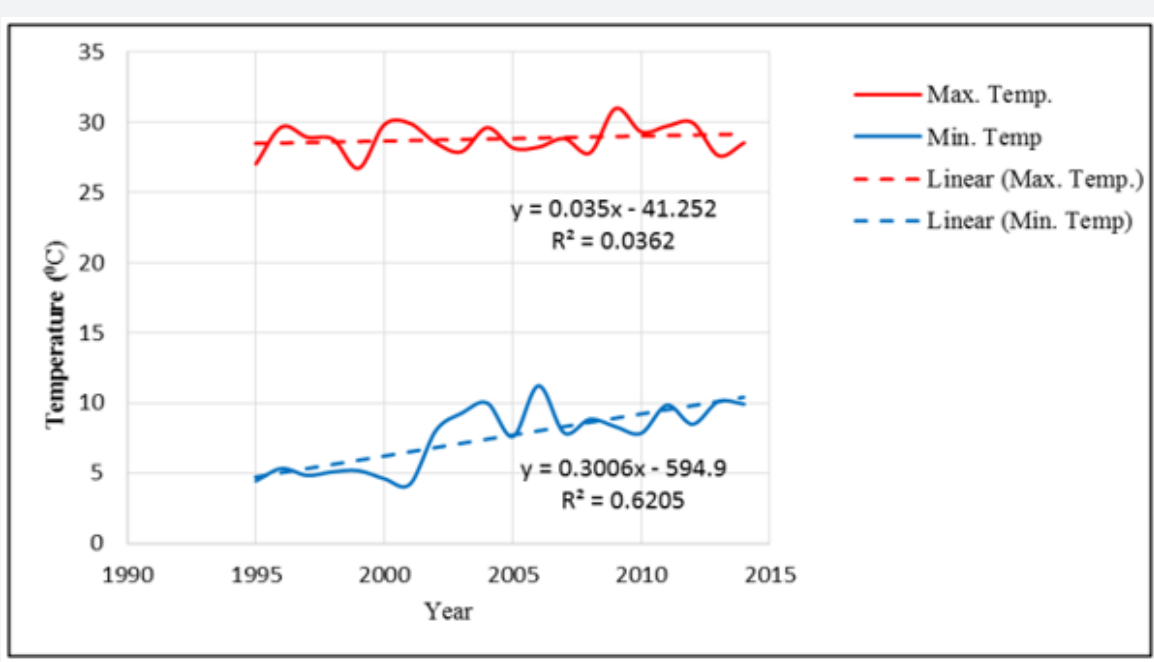

Figure 4 : Annual Temperature variability (Max. and Min.) Temperature Trends.

Effects of climate variability on coffee production

The amount of rainfall received and temperature significantly affect coffee production in the study area at less than $1 \%(\mathrm{P}<3.027)$ and $(\mathrm{P}<2.015)$ percent probability level respectively (Table 2$)$. The Effects of temperature and rainfall variability on coffee production result of the regression analysis; the coefficient for temperature is negative which suggests that a one ${ }^{\circ} \mathrm{C}$ increase in the temperature is associated with a reduction of $43 \mathrm{~kg}$ in coffee production; while the coefficient of rainfall is positive which suggests that a one $\mathrm{mm}$ increase of rainfall associated with an increase of $.079 \mathrm{~kg}$ in coffee production keeping other things held constant [12-14].
Table 2: Effect of temperature and rainfall variability on coffee production.

\begin{tabular}{|c|c|c|c|c|c|}
\hline Yields & Coef. & Std. Err. & T & P>t & Beta \\
\hline Temp & -43.60378 & 17.98645 & -2.42 & $3.027^{* * *}$ & -0.42537 \\
\hline $\mathrm{RF}$ & 0.0793803 & 0.0294616 & 2.69 & $2.015^{*}$ & 0.472764 \\
\hline cons & 1574.771 & 488.7756 & 3.22 & 0.005 & \\
\hline
\end{tabular}

***Significant at $<1 \%$ level, R-squared $=0.5987$, Root MSE $=53.113, \mathrm{~F}$ $(2,17)=12.68$, Adj R-squared $=0.5515$, Prob $>F=0.0004$, Number of obs $=20$.

An option to the regress command called beta, which would give the standardized regression coefficients. The beta coefficients 
were used by to compare the relative strength of the predictors within the model. The beta coefficients are the coefficients that would obtain if the outcome and predictor variables were all transformed standard scores, also called z-scores, before running the regression. Because the coefficients in the Beta column are all in the same standardized units you can compare these coefficients to assess the relative strength of each of the predictors. In this study, rainfall has the largest Beta coefficient, 0.47 (in absolute value), and temperature has the smallest Beta, -0.425 . Thus, a one standard a one standard deviation increase in rainfall leads to a 0.47 standard deviation increase in coffee yield and a one standard deviation increase in temperature leads to a -0.425 standard deviation decrease in coffee production, with the other things held constant (Table 2).

\section{Determinants of farmers' choice of adaptation strategies to climate variability}

Hence, out of the eight variables analyzed, the coefficients of five variables, namely perception, education level, farm size, access to credit service and total family size were significantly affected households' decision to take climate variability adaptation strategies in the study area. The remaining three explanatory variables age, sex, training and extension services were not significant. This result is similar to the findings of [7] which were conducted in Nile Basin of Ethiopia (Table 3).

Table 3: Parameter Estimates of the Logit model of Adaptation Strategies.

\begin{tabular}{|c|c|c|c|c|c|}
\hline Adptnm & Coef. & Std. Err. & $\mathbf{Z}$ & P>t & $\begin{array}{c}\text { Marginal } \\
\text { effects } \\
\text { (dy/dx) }\end{array}$ \\
\hline Age & 0.004735 & 0.047457 & 0.1 & 0.921 & 0.000628 \\
\hline Sex & 0.386595 & 0.694759 & 0.56 & 0.578 & 0.030077 \\
\hline Prcpn & 1.585963 & 0.815164 & $1.95^{* *}$ & 0.052 & 0.134994 \\
\hline Educlv & 1.004169 & 0.384286 & $2.61^{* * *}$ & 0.009 & 0.092915 \\
\hline Fmsize & 0.994263 & 0.228648 & $4.35^{* * *}$ & 0 & 0.120731 \\
\hline Acscrt & 1.256709 & 0.75192 & $1.67^{*}$ & 0.095 & 0.085884 \\
\hline Texns & 0.301705 & 0.668372 & 0.45 & 0.652 & 0.030902 \\
\hline Tfasize & 0.300339 & 0.172618 & $1.74^{*}$ & 0.082 & 0.018462 \\
\hline _cons & -11.7 & 2.88582 & -4.05 & 0 & \\
\hline
\end{tabular}

***Significant at $<1 \%$ level, ${ }^{* *}$ Significant at $<5 \%$ level, *Significant at $<10 \%$ level, LR chi ${ }^{2}(8)=95.79$, Prob $>\mathrm{chi}^{2}=0.0000$, Number of obs $=$ 145 , Pseudo $R^{2}=0.5816$, Log likelihood $=-34.459507$.

\section{Conclusion}

The findings of this research show that in Abeshege woreda, almost all of the farmers were aware about the change in the level of precipitation and temperature during the last 20 years. The adaptation strategies such as soil and water conservation, small scale irrigation, changing planting date and improved crop and livestock variety are the most commonly practiced adaptation strategies to climate variability by the households. The results of the logit regression model show that perception about climate variability, educational level of the household head, farm size owned by the household, access to credit service, and total family size of the household are among the factors which are positively affect the farmers decision to take climate variability adaptation strategies. The Pearson correlations result show that the amount of rainfall received and temperature significantly affect coffee production in the study area and the correlation relationship between temperature and yield was Strong negative relationship, while rainfall and yield have strong positive relationship.

Therefore, the government should first understand the farmers' preferences for climate variability adaptation together with demographic, socio-economic and institutional factors in designing and implementing appropriate policy response to reduce the effects of climate variability in the study area. In addition, addressing the barrier to climate variability adaptation is also very important.

\section{References}

1. Joel Iscaro (2014) The Impact of Climate Change on Coffee Production in Colombia and Ethiopia. Global Majority E-Journal 5(1): 33-43.

2. Kifle B, Demelash T (2015) Climatic Variables and Impact of Coffee Berry Diseases in Ethiopian Coffee Production. Biology Agri and Health crare 5(7): 55-64.

3. Hameso S (2012) Development Challenges in the Age of Climate Change: The Case of Sidama. Ethiopia.

4. SAZ (2005) SNNPR Livelihood Zone Reports, Abeshege Woreda, gurage Administrative Zone.

5. Yemane (1977) Determination of appropriate Sample Size.

6. Mukherjee K, Pandey DM, Vidyarthi AS (2012) Molecular Dynamics Simulation of Rap1 Myb-type domain in Saccharomyces cerevisiae. Bioinformation 8(18): 881-885.

7. Deressa T, Rashid M Hassan, Claudia Ringler, TekieAlemu, Mohamud Yusuf (2009) Determinants of farmers choice of adaptation methods to climate change in the Nile Basin of Ethiopia. Journal global environmental change 19(2): 248-255.

8. Orindi VA, Eriksen S (2005) Mainstreaming adaptation to climate change in the development process in Uganda. African Centre for Technology Studies (ACTS).

9. H Mongi, AE Majule, JG Lyimo (2009) Vulnerability and adaptation of rain fed agriculture to climate change and variability in semi-arid Tanzania. African Journal of Environmental Science and Technology 4(6): 371-381.

10. IPCC (2001) Climate change 2001: Impacts, adaptation, and vulnerability. intergovernmental panel on climate change. Cambridge University Press, Cambridge, UK, pp. 1042.

11. Dinku Tufa, Kidane Asefa, Kinfe Hilemariam, David Grimes, Stephen Connor (2011) Improving availability, access and use of climate information. Bulletin of the World Meteorological Organization 60(2): 80.

12. FDRE (2008) Summary and Statistical Report of the 2007 Population and Housing Census. Population Size by Age and Sex. Population Census Commission, Addis Ababa, Ethiopia, pp. 115.

13. Gujarati DN (2004) Basic Econometrics. (4 $4^{\text {th }}$ edn), McGraw-Hill Company, USA, pp. 1024.

14. Yohannes Gebre Michael, Mebratu Kiffle (2009) Local innovation in climate change adaptation by Ethiopian pastoralists. ProlinnovaEthiopia and pastoralist forum Ethiopia, Final Report p. 1-29. 


Your next submission with Juniper Publishers
will reach you the below assets
- Quality Editorial service
- Swift Peer Review
- Reprints availability
- E-prints Service
- Manuscript Podcast for convenient understanding
- Global attainment for your research
- Manuscript accessibility in different formats
( Pdf, E-pub, Full Text, Audio)
- Unceasing customer service
Track the below URL for one-step submission
https://juniperpublishers.com/online-submission.php

